2015-05-18

\title{
Sensitive Chaos
}

\author{
Strang, David
}

http://hdl.handle.net/10026.1/12014

10.1162/LEON_a_01012

Leonardo

MIT Press - Journals

All content in PEARL is protected by copyright law. Author manuscripts are made available in accordance with publisher policies. Please cite only the published version using the details provided on the item record or document. In the absence of an open licence (e.g. Creative Commons), permissions for further reuse of content should be sought from the publisher or author. 


\section{SENSITIVE CHAOS}

\author{
David Strang \\ Plymouth University \\ Music
}

\author{
Third author \\ Plymouth University \\ Drake Circus \\ Devon \\ PL4 8AA
}

\begin{abstract}
This paper describes the life (and death) of the interface in the installation 'Tiny Moments' by David Strang. 'Tiny Moments' is a sound and light interactive installation that explores natural phenomena surrounding heat, ice and presence / proximity. This installation explores the role of the interface in computer interaction in a way beyond simple hardware devices being available to "users". The work reacts to all people who engage with it (merely being present) and as the number of people rise the work responds due to changes in temperature of the site that thus increase the frequency of the cycle of flashes of heat from within the ice that come from the lights. What is created is a space filled with ever changing rhythms of light and sound in complete synchronicity that no user feels to have any control of.
\end{abstract}

\section{INTRODUCTION}

The title of this paper is borrowed from the title of an Arts and Science exhibition at ICC Museum, Tokyo in 1997. It is borrowed not only as it suits the work to be discussed here but also that it is from an exhibition exploring physical-world phenomena in much the same way as 'Tiny Moments' does.

Throughout the following text I aim to discuss the core artwork, 'Tiny Moments', looking at the technology involved and its make up as well as exploring the potential of these alternative interfaces particularly across the fields of science and arts.

\section{TINY MOMENTS}

"In place of high-tech and ultramodern creations, here we have artworks of a kind that have moved mankind since time immemorial, and excited his aesthetic sense and curiosity."1

This quote from the curatorial statement for the "Sensitive Chaos" exhibition outlines my initial interest in exploring the use of the materials for this artwork. At the outset the work was a set of experiments using water and ice along with contact microphones and hydrophones to bring out new details of these materials to the ear. As part of these tests I was obliged to try out

'Sakane, I. " 'Sensitive Chaos' Curatorial Statement" in Wilson, S. "Information Arts: Intersections of Art, Science and Technology" p.258 the popular act of freezing microphones and then listening to the thawing process, inspired mostly by artists or sound sculptors such as Max Eastley who have been working with the natural rhythms of water and ice for some time. It was clear that this process of amplifying the tiny pops and crackles of air escaping from within ice was an exciting way to create sound / music along with the more obvious possibility of rhythms from falling droplets of melting ice. The challenge was how to make something more interesting from these parts - the sounds can already be clearly imagined in the mind without actually hearing them. To progress the work beyond a field recording / listening exercise I began to look into ways of controlling certain disturbances within the ice (added heat) which began to bring in interesting research around interaction, nonlinear theory and hardware and software.

"I am not investigating in the object world, I am investigating sensitivity." 2 The works of Felix Hess were a major catalyst in deciding to freeze small light bulbs along with the contact microphones. His "Icelamp", as described in his book "Light as Air", showed a beautiful way to interfere with the natural process of ice melting by using an external agent (in this case air pressure). Fluctuations in air pressure were linked to the bulb encased in ice to create a glowing, pulsating lamp that eventually melted away the exterior. Turning on a light would begin to thaw the ice rapidly from the inside thus enabling me to speed up the melting process but this would quickly end and the aim was now to create an installation where people could experience multiple instances of ice and light and sound. Using certain technologies in conjunction with the ice and lights and microphones goes slightly in the face of the quote above by Sakane but I believe that it proves the potential for increased interaction between the physical world and the digital. "Art pursues invention and so explores the limits of its media to forge new possibilities and discover unexpected directions." ${ }^{3}$ Using Max/MSP (see Figure 1) and Arduino (see Figure 2) to interface with the ice was a relatively simple system but it enabled the work to realize its full potential.

${ }^{2}$ Hess, F. "Light as Air” p.35

${ }^{3}$ Evens, A. "Sound Ideas: Music, Machines, and Experience" p.82 


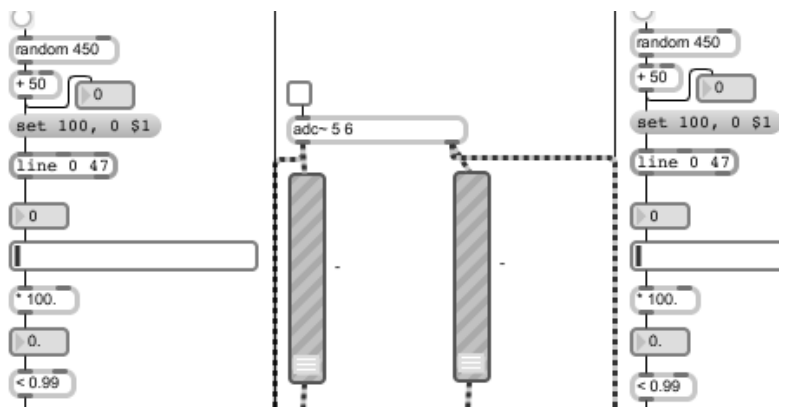

Figure 1. Screenshot of Max/MSP graphical interface.

The system created for "Tiny Moments" involved suspending multiple blocks of ice from the ceiling throughout a space. Beneath each block was a large metal bowl, also suspended from the ceiling. Attached to the underside of each bowl was a contact microphone connected to a mixer going into Max/MSP. As a droplet of water landed in the bowl it would be amplified throughout the space with added reverb from Max whilst, at the same time, sending a signal to the corresponding light bulb via Arduino and switching it on for up to 0.5 seconds. The resulting work is a space filled with tiny instances of flashing lights in connection to the large reverberant sound of water droplets.

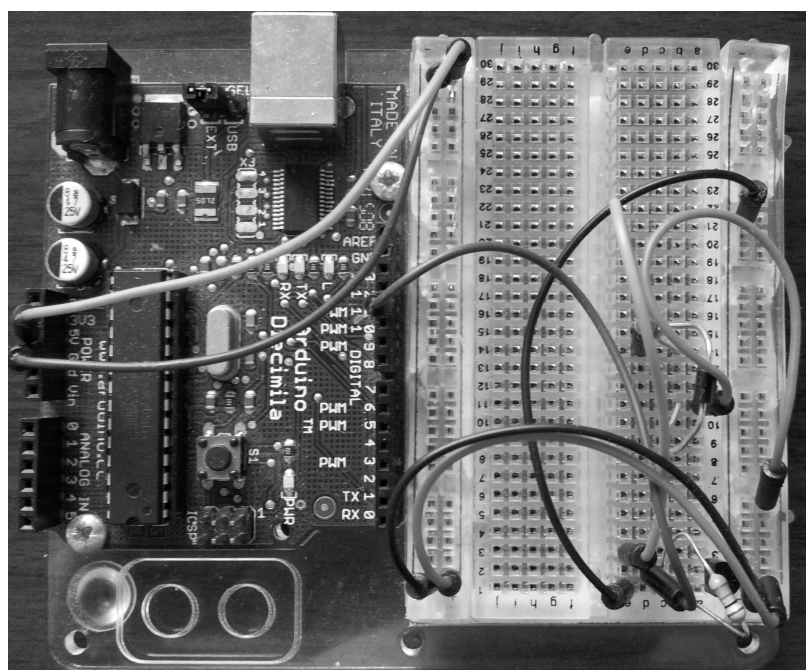

Figure 2. Arduino board with breadboard.

This setup throughout the space enabled the visitor or "user" to become completely immersed in not only the work but in the interface of the work as it hung directly around them. The sonic element of the work was not distributed across a large network of speakers or involved any surround sound setup - it simply used one stereo pair of speakers at either end of the space. The sense of complete immersion in the work did not come only from the sound (as in many cases of immersive interactive work) but from the feeling of being inside the system whilst standing in the space.
Immersion became hugely important for contemporary artists and especially for those exploring interactive and responsive environments. As Mark Rothko states "To paint a small picture is to place yourself outside your experience, to look upon an experience as a stereopticon view with a reducing glass. However you paint the large pictures, you are in it." The same can be thought of in terms of the interface in 'Tiny Moments' as well as in more recent developments such as Microsoft's Kinect.

At the core of the installation was always the visitor and how they would feel faced with the work. The work requires the visitor to be very patient, as nothing is made clear. The space is completely dark and the flashes of light happen so quickly it is extremely difficult to pick out what is happening. This builds up the intrigue in the work as the unknown surrounds the visitor. "What I can name cannot really prick me. The incapacity to name is a good symptom of disturbance." With time the visitor becomes more connected to the work and will discover the ice melting from above but the other components (the software and hardware) are not visible. For the patient visitor they are not only rewarded with a certain understanding of the parts but also becoming part of the system and experiencing the changes in rhythms and speed of the falling droplets. They're presence in the space is enough to cause a slight disturbance in the work as their body heat raises the temperature in the room. As more people visit and stay in the space the affect on the ice increases so the light bulb, the environment and the people are now connected through the system of ice, Max/MSP and Arduino. Going back to my earlier point about how to raise the interest in the work beyond being a listening exercise - the work now plays on the knowledge of the visitor and their surroundings. The water droplets are not processed beyond recognition (just some added reverb) but the visitor cannot predict the patterns for the work as the disturbances in the place increase. In the curatorial statement for the exhibition "Turbulent Landscapes" (ICC, Tokyo) Melissa Alexander quotes from Tom Stoppard's "Arcadia" pointing out that "We can't even predict the next drip from a dripping tap when it gets irregular. Each drip sets up conditions for the next, the smallest variation blows prediction apart, and the weather will always be unpredictable." 6

Two works of particular influence in regards to the disturbance by the visitor and their required patience are "The Listening Room" by David Cunningham and "It's in the Air" by Felix Hess. In "The Listening Room" a

${ }^{4}$ Rothko, M. "I Paint Very Large Pictures: Excerpt from Symposium on How to Combine Architecture, Painting and Sculpture" in Ascott, R. ed. "Engineering Nature: Art \& Consciousness in the Post-Biological Era" p.139

${ }^{5}$ Barthes, R. "Camera Lucida" p.51.

${ }^{6}$ Stoppard, T. "Arcadia" in Wilson, S. "Information Arts: Intersections of Art, Science and Technology" p.237 
feedback system is set up by plugging a microphone into a speaker via a noise gate. Quickly the feedback rises and once it hits a threshold set on the noise gate the system is cut leaving the sound to reverberate in the space and fall back down below the threshold where the gate opens and the cycle continues. What Cunningham noticed about the work was that the sounds changed as the environment changed, a hot day produced different sounds to a cold one and when a visitor entered they immediately became linked into the system and affected its output. "It's in the Air" by Hess explored the disturbances in the air by a person as well but also required patience from them. Spread out across the floor of a room would be hundreds of tiny wind vanes made from Japanese rice paper. As a visitor entered the space and stood on one spot slowly, the wind vanes would turn to point towards them. Both works explore the disturbance in the system that influenced my work along with the communication theory schematic by Shannon (see Figure 3).

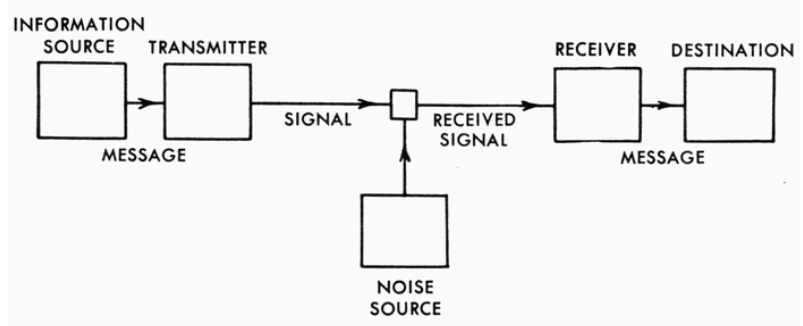

Figure 3. Claude Shannon's Mathematical Theory of Communication

In all of these works the visitor or user is instantly plugged into the system as an element of noise. The light bulbs encased in the ice act as another noise source in 'Tiny Moments' one that is involved in a loop within the system itself. Both the visitor and the light and any fluctuation by either will affect the system. "This alteration of behavior, be it one of excitation or placation, will be driven by an intention of bringing the system to equilibrium or to drive it into an unsteady or chaotic state." 7 Like many interfaces there is a feedback to the user and a feed in from the user where each affects the other.

\section{CONCLUSION}

As an interactive artwork 'Tiny Moments' works subtly and slowly on the visitor - not exposing the technical functions within the system but purely interacting with any visitor and adjusting according any presence. This is where a certain magic lies within the work as whether you are trying to work out how it works or have worked

${ }^{7}$ Paine, G. "Interactive, Responsive Environments: A Broader Artistic Context" in Ascott, R. ed. "Engineering Nature: Art \& Consciousness in the Post-Biological Era" p.141 out the system it still surprises and won't become fixed for any length of time. Behind this is the knowledge that it cannot exist forever and is constantly in a state of decay that is increased with every droplet and every person. I am regularly reminded of a quote by artist Paul DeMarinis in "Information Arts: Intersections of Art, Science and Technology" where he says "I wouldn't be comfortable with a piece that created an illusion by conventional means. For me the real illusions are the ones that still mystify even when the technology is revealed and explained." 8 The tools used in making this work enable the artist to explore and create like never before, to build new interfaces between almost anything. Arduino has bridged a gap between the digital, arts and sciences and other disciplines too. Allowing us to interact with our houseplants to know if they are thirsty or too hot. With this advancement in technology and its availability comes such great potential for the user and the interface to come together in different, unexpected ways. "Reading the body alone is not enough. Actively feeling the world - both the physical and the virtual - will enhance the technological combination of the user with his personal terminal." We can plug into nature's rhythms and create biological interfaces exploring chaos.

'Tiny Moments' exists as a sensitive interface that accurately detects presence and movement of people who are not fully aware of the control they have over the system.

\section{REFERENCES}

[1] Sakane, I. “" 'Sensitive Chaos' Curatorial Statement" in Wilson, S. Information Arts: Intersections of Art, Science and Technology. MIT Press, 2002.

[2] Hess, F. Light as Air. Stadtgalerie Saarbrucken, 2003.

[3] Evens, A. Sound Ideas: Music, Machines, and Experience. University of Minnesota Press, 2005.

[4] Rothko, M. "I Paint Very Large Pictures: Excerpt from Symposium on How to Combine Architecture, Painting and Sculpture" in Paine, G. "Interactive, Responsive Environments: A Broader Artistic Context" in Ascott, R. ed. Engineering Nature: Art \& Consciousness in the Post-Biological Era. Intellect, 2006.

[5] Barthes, R. Camera Lucida. Vintage, 1993.

${ }^{8}$ DeMarinis, P. ICC Journal "Interview with Paul Demarinis" in Wilson, S. "Information Arts: Intersections of Art, Science and Technology" p.399

${ }^{9}$ Stenslie, S. "Symbiotic Interactivity in Multisensory Environments" in Ascott, R. ed. "Engineering Nature: Art \& Consciousness in the Post-Biological Era" p.154 
[6] Stoppard, T. "Arcadia" in Wilson, S. Information Arts: Intersections of Art, Science and Technology. MIT Press, 2002.

[7] Paine, G. "Interactive, Responsive Environments: A Broader Artistic Context" in Ascott, R. ed. Engineering Nature: Art \& Consciousness in the Post-Biological Era. Intellect, 2006.

[8] DeMarinis, P. ICC Journal "Interview with Paul Demarinis" in Wilson, S. Information Arts: Intersections of Art, Science and Technology. MIT Press, 2002.

[9] Stenslie, S. "Symbiotic Interactivity in Multisensory Environments" in Ascott, R. ed. Engineering Nature: Art \& Consciousness in the Post-Biological Era. Intellect, 2006. 